\title{
The Utility of Transbronchial Needle Aspiration and Conventional Diagnostic Procedures in the Diagnosis of Bronchogenic Carcinoma
}

\author{
Mahesh Kumar Mahich ${ }^{1}$, Ghanshyam Rathi ${ }^{2}$, Mahendra Kumar ${ }^{3}$ \\ ${ }^{1}$ Assistant Professor, Department of T.B. \& Chest Hospital, Badi, R.N.T. Medical College, Udaipur, Rajasthan, India, ${ }^{2}$ Ex Prnicipal Specialist, Department of T.B. \& \\ Chest Hospital, Badi, R.N.T. Medical College, Udaipur, Rajasthan, India, ${ }^{3}$ Professor, Department of T.B. \& Chest Hospital, Badi, R.N.T. Medical College, Udaipur, \\ Rajasthan, India.
}

\section{Abstract}

Background: Lung tumours often present as masses or nodules situated beyond the range of even new-generation fibreoptic bronchoscopes. The aim of this study to compare diagnostic yield of TBNA with CDP for diagnosis of Bronchogenic carcinoma. Subjects and Methods: The study was carried out and data were gathered in a prospective fashion and all the data were reviewed retrospectively. All the suspected patients were diagnosed on the basis of clinical, radiological and video bronchoscopic examination (CDP+TBNA); and further diagnosis was confirmed on the basis of histological and / or cytological examination. Results: In the present study, after TBNA \& CDP, the overall diagnostic yield for carcinoma was $93 \%$ (28/30). CDP was diagnostic in $100 \%$ cases of EML and only $70 \%$ in SPD. TBNA provided an additional diagnostic yield of $30 \%$ in Cases of SPD where CDP was not possible for taking samples, which is seen to be statistically significant $(\mathrm{p}=0.02)$. Conclusion: We conclude that TBNA is a safe procedure that should be routinely used to increase diagnostic yield in patients with EML or SPD.

Keywords: TBNA, CDP, EML, Bronchial Carcinoma.

Corresponding Author: Dr. Ghanshyam Rathi, Ex Prnicipal Specialist, Department of T.B. \& Chest Hospital, Badi, R.N.T. Medical College, Udaipur, Rajasthan, India.

Received: August 2019

Accepted: August 2019

\section{Introduction}

Lung Cancer is the leading cause of cancer deaths worldwide. The disease is more common in men than women, although this difference has become smaller. Recently, mortality rates have been falling in men of all ages. Although the incidence of the disease continuous to claim in the older age. ${ }^{[1]}$ The incidence of the lung cancer is globally increasing $0.5 \%$ each year as a result of tobacco consumption rates. ${ }^{[2]}$ Lung cancer is responsible for $12.8 \%$ of cancers and $17.8 \%$ of cancer related deaths worldwide. ${ }^{[3]}$ In recent past, an increasing trend in the incidence of primary lung cancer has been reported from various parts in India. ${ }^{[4]}$ Early diagnosis and treatment of the tumor is the only hope of cure at current state of knowledge. ${ }^{[5]}$

The cell type pattern had varied in different studies. While squamous cell variety is the commonest seen in about one third of patient, there has been a definite increase in small cell carcinoma and adenocarcinoma in recent years. The cell type is largely influenced by smoking habits, age and sex. Squamous cell carcinoma occur almost exclusively in smokers and in males, females have an inverse increase in adenocarcinoma. The cell type pattern also varies with age. ${ }^{[6]}$

Lung tumours often present as masses or nodules situated beyond the range of even new-generation fibreoptic bronchoscopes. The low diagnostic yield of the standard combination of bronchial washing, bronchial brushing and endobronchial biopsy in these abnormalities often requires the use of higher risk procedures. In order to improve the yield of bronchoscopy for diagnosis of mediastinal masses and nodules the transbronchial needle aspiration (TBNA) technique is being employed in several centres. ${ }^{[7-9]}$ TBNA has been shown to be useful in the diagnosis of primary pulmonary lesions, ${ }^{[9-12]}$ in addition to its use as a staging procedure in patients with lung cancer and mediastinal adenopathy. ${ }^{[11]}$

Conventional transbronchial needle aspiration (TBNA) is a beneficial, safe, and minimally invasive bronchoscopic technique. It was first introduced by Wang et al in the late 1970s. This method is usually performed through a flexible bronchoscope and provides cytologic or histologic sampling of mediastinal lesions that lie adjacent to the tracheobronchial tree. ${ }^{[13-15]}$ Particularly in the presence of peribronchial and submucosal lesions and vascular lesions, diagnosis with CDT such as $\mathrm{BW}, \mathrm{BB}$, and $\mathrm{FB}$ is more difficult. However, applying a needle into the lesion provides access to lower layers of the bronchus and adjacent lesions. Despite its advantages in diagnosis, TBNA is still an underutilized procedure in many centers because of the risk of damage to the bronchoscope, need for experienced 
staff, and high cost. ${ }^{[14]}$ The aim of this study to compare diagnostic yield of TBNA with CDP for diagnosis of Bronchogenic carcinoma.

\section{Subjects and Methods}

The study was carried out and data were gathered in a prospective fashion and all the data were reviewed retrospectively. Patients came to the Respiratory Medicine OPD and Indoor of TB \& Chest Disease Hospital, attached to RNT medical college, Udaipur, Rajasthan, with suspicion of bronchogenic carcinoma were registered for the study.

A detailed clinical history with complete physical examination was carried out in all the patients including the symptoms, duration of illness, smoking history; as per Performa given.

All the suspected patients were diagnosed on the basis of clinical, radiological and video bronchoscopic examination (CDP+TBNA); and further diagnosis was confirmed on the basis of histological and / or cytological examination.

\section{Inclusion Criteria}

Patients found to have endobronchial disease, hilar or mediastinal lymph nodes (Mediastinal masses and adenopathy) on Chest X-Ray or computed tomography. Patients found to have EML or SPD during routine fiberoptic bronchoscopy has been entered in the study.

\section{Exclusion Criteria}

- Patients with pre-existing known malignancy.

- Patients in whom bronchoscopy was contraindicated were excluded from the study.

Samples were collected from all patients bronchial washings (BW), brush biopsy (BB), EBB, and TBNA. The procedural sequence between $\mathrm{EBB}$ and TBNA was randomly allocated to either of the two sequences:

(1) BW and TBNA, or (2) BW, EBB, BB and TBNA

\section{Sample Collection}

\section{Following specimen has been collected:}

Bronchial Washing: This was the first sample collection before endobronchial biopsy or bronchial brushing with instillation of normal saline $(0.9 \% \mathrm{NaCl}$ solution), when growth was visualize, the bronchoscope was fixed in close proximity and 10 to $15 \mathrm{ml}$ normal saline was introduced through the internal channel of the bronchoscope. The material was immediately be sucked out again and has been collected in a sterile specimen TRAP bottle to be placed in the suction pathway and bronchoscope. The bronchial washing was centrifuged and the supernatant was discarded. The sediment was smeared over 4 to 5 glass slides.

Air dry slides was fix in 70\% ethyl alcohol, later on stain with M.G.G stain (May Grunwald and Giemsa stain) for malignant cells.

\section{TBNA/EBNA:}

(A) To obtain adequate TBNA specimens three passes for endobronchial vascular lesions and two passes for mediastinal masses and adenopathy with the cytology needle (19 or 21 -gauge; Length $15 \mathrm{~mm}$ to $18 \mathrm{~mm}$ ) was performed. Both smear preparation and flushed aspirates was sent for cytology evaluation and ROSE was not be performed because of unavailability of facility in the hospital and limited resources.

(B) For obtaining specimens from EML, the needle was directly inserted into the lesion, avoiding necrotic areas as practiced with other CDP.

(C) For submucosal lesions, the needle was partially introduced at an angle of $45^{\circ}$ into the bronchial wall, whereas complete penetration through the wall was performed in the case of extrinsic compression from peribronchial disease7. The bronchoscopic findings has been correlated with the anatomic location of the peribronchial lesion on CT scans of the chest.

Bronchial Brushing: The brushing was taken by Nylon brush-BC-9C, an area of suspected malignancy has been brushed 4 to 5 times; and smeared directly on glass slide, smears are immediately fixed in $70 \%$ alcohol and stained by Papanicolau's/MGG stain method.

Bronchial biopsy: When an endobronchial growth was seen or any abnormal area was seen on bronchoscopic examination, it was biopsied 3 to 4 times in order to provide an adequate material for histopathological examination with the help of biopsy forcep-FB-20C. Then the biopsy specimen was placed in $10 \%$ formalin vial and sent for histopathological examination.

Results of various specimens were compared - Cytologic analysis has been considered positive only when large numbers of definitely malignant cells was present.

The primary outcome measures of this study was to establish the diagnostic yield of TBNA and compare with CDP (combination of BW, BB, and EBB). Furthermore, we were analyze the impact on diagnostic yield from each of the individual procedures as well as on the basis of the nature of the lesion, ie, EML or SPD. We were also study whether presence of lesion in upper lobes and sequence of performing TBNA and EBB influence the diagnostic yield. Any procedure-related complications and damage to the bronchoscope was also be noticed.

\section{Results \& Discussion}

The present study showed that the maximum number (70\%) of patients were belonged to 50-60 years and above age group [Table 1].

Maximum aspiration for sampling were performed on the right side at $4 \mathrm{R}$ station $(43.33 \%)$ followed by $4 \mathrm{~L}(20 \%)$ and $13.33 \%$ from 7 and $11 \mathrm{R}$ stations. 10R was the least with only $6.66 \%$ cases. In this study TBNA needle aspiration was performed more on right side $(67.75 \%)$ compared to other nodal station [Table 2].

In the present study, after TBNA \& CDP, the overall diagnostic yield for carcinoma was 93\% (28/30). 18 (60\%) cases were confirmed as NSCLC followed by $8(26.66 \%)$ cases of SCLC. 1 case (3.33\%) each of NHL, TB, Anaplastic carcinoma and Nonspecific inflammation was also diagnosed in the study [Figure 1].

CDP was diagnostic in $100 \%$ cases of EML and only $70 \%$ 
in SPD. TBNA provided an additional diagnostic yield of $30 \%$ in Cases of SPD where CDP was not possible for taking samples, which is seen to be statistically significant (p=0.02) [Table 3].

Overall diagnostic yield in the present study was $93 \%$. TBNA was diagnostic in $87 \%$ and it was solely positive in $31 \%$ cases [Table 4 ].

\section{Table 1: Age wise distribution}

Table 1: Age wise distribution
\begin{tabular}{|l|l|l|l|l|}
\hline Years & Male & Female & Total & Percent \\
\hline $30-40$ & 0 & 0 & 0 & $0 \%$ \\
\hline $41-50$ & 7 & 2 & 9 & $30 \%$ \\
\hline $51-60$ & 9 & 1 & 10 & $33.33 \%$ \\
\hline$>60$ & 10 & 1 & 11 & $36.66 \%$ \\
\hline Total & 26 & 4 & 30 & - \\
\hline
\end{tabular}

\section{Table 2: Site of Nodal / Mass TBNA (Station Wise)}

\begin{tabular}{|l|l|l|}
\hline Site of TBNA & No. & \% \\
\hline $2 \mathrm{R}$ & 1 & $3.33 \%$ \\
\hline $4 \mathrm{R}$ & 13 & $43.33 \%$ \\
\hline $4 \mathrm{~L}$ & 6 & $20 \%$ \\
\hline 7 & 4 & $13.33 \%$ \\
\hline $10 \mathrm{R}$ & 2 & $6.66 \%$ \\
\hline $11 \mathrm{R}$ & 4 & $13.33 \%$ \\
\hline Total & 30 & - \\
\hline
\end{tabular}

\begin{tabular}{|c|c|c|c|c|c|}
\hline \multirow{2}{*}{$\begin{array}{l}\text { Condition } \\
(n=30)\end{array}$} & \multicolumn{2}{|c|}{ CDP } & \multicolumn{2}{|c|}{ CDP + TBNA } & \multirow{2}{*}{$\begin{array}{l}\mathbf{p} \\
\text { Value }\end{array}$} \\
\hline & No. & $\%$ & No. & $\%$ & \\
\hline EML $(n=14)$ & 14 & $100 \%$ & 14 & $100 \%$ & $p<0.05$ \\
\hline SPD $(n=20)$ & 14 & $70 \%$ & 20 & $100 \%$ & $p=0.02$ \\
\hline
\end{tabular}

\section{Table 4: Diagnostic yield of TBNA, Washing, Brushing \& EBB} $(\mathrm{n}=28)$

\begin{tabular}{|l|l|l|}
\hline Procedure & Positive Cases & \% \\
\hline Bron. Wash $(\mathrm{BW})$ & $8 / 30$ & 27 \\
\hline Bron. Brushing(BB) & $14 / 30$ & 47 \\
\hline EBB & $9 / 15$ & 60 \\
\hline TBNA & $26 / 30$ & 87 \\
\hline EBB+BW+BB & 20 & 67 \\
\hline TBNA+BW+BB & 28 & 93 \\
\hline TBNA+EBB+BW+BB & 28 & 93 \\
\hline
\end{tabular}

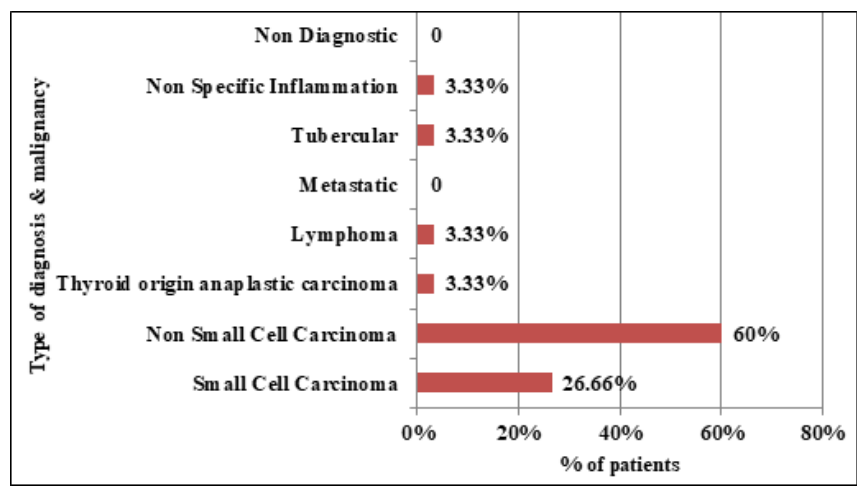

Figure 1: Types of Diagnosis and malignancy

\section{Discussion}

In the present study, $70 \%$ patients were belonged to 50 $60 y e a r$ and above age group. Out of that $(n=30), 26$ were male and only 4 were female. These findings were consistent with other study.

The average age was 58.07 year in the study has been quite similar to other study. The male: female ratio in present study M:F: 6.5:1 quite comparable to other studies (Narang et al 1977 and Malhotra et al 1986). ${ }^{[16,17]}$

The overall diagnostic yield was increased with the use of TBNA technique. In bronchoscopic procedure in suspected cases of malignancy in various studies. In the present study, the additional diagnostic yield was increased from $67 \%$ to $93 \%(26 \%)$ which is very much similar to other studies i.e. Benan Caglayan et al (26\%) and Ashok Dasgupta et al $(20 \%)$ and it was higher to Thida Win et al $(6 \%)$ and Frank Reichenberger et al (16\%). ${ }^{[18-21]}$ This may be because of highly selective cases for procedure.

In cases of SPD, the additional diagnostic yield was increased from $70 \%$ to $100 \%(30 \%)$ which were similar to the studies of Ashok Dasgupta et al (31\%) and Benan Caglayan et al (27\%). ${ }^{[18,19]}$ This defines the use of TBNA increase the diagnostic yield of biopsy with minimal risk.

Bronchial washing (BW) was also performed in all 30 cases. A positive result was obtained in $8(27 \%)$ cases and were never positive when any of the other procedures result were negative (Kvale et al, ${ }^{[2]}$ Ashok Dasgupta et al). ${ }^{[19]}$

Bronchial brushing (BB) was also used in all 30 cases with a positive results in $14(47 \%)$ cases. In $1(7 \%)$ case this was the only technique with a positive result.

Endobronchial biopsy (EBB) was used in 15 (50\%) cases and lead to a diagnosis in $9(60 \%)$ cases. It was solely positive technique in $1(11 \%)$ case. For all the 30 cases, $\mathrm{BW}, \mathrm{BB}$ and $\mathrm{EBB}$ together had a diagnostic yield of $67 \%$. The TBNA alone provide a positive result in $31 \%$ of cases. The addition to CDP, use of TBNA increase the overall diagnostic yield from $76 \%$ to $93 \%$. In cases of SPD the additional use of TBNA increase the diagnostic yield from $70 \%$ to $100 \%$. That results are similar to previous studies (Ashok Dasgupta et al, Benan Caglayan et al). ${ }^{[18,19]}$

The diagnostic yield of BW was $27 \%$ which was least in the present study. The similar result were also obtained in previous studies i.e. Ashok Dasgupta et al, ${ }^{[19]}$ (27\%), Frank Reichenberger et al (22\%), ${ }^{[21]}$ David A. Schenk et al, ${ }^{[23]}$ (29\%) but the higher result was found in study of Thida Win et al (45\%). ${ }^{[20]}$ In the present study BW did not positive when any of the other test results were nagetive while it was solely diagnostic in studies i.e. Frank Reichenberger et al (6\%), ${ }^{[21]}$ Thida Win et al (4\%). ${ }^{[20]}$

The diagnostic yield of BB was $47 \%$ in the present study. This result is similar with the previous studies of Ashok Dasgupta et al 1999 (55\%) and David A. Schenk et al 1987 $(40 \%) .{ }^{[19,23]}$ The yield of BB was higher with the study of Frank Reichenberger et al, ${ }^{[21]} 1999(30 \%)$ and Thida Win et al $2003(27 \%) .{ }^{[20]}$ The BB was solely diagnostic in $1(7 \%)$ case and it was consistent with other studies i.e. Ashok Dasgupta et al $1999(6 \%)$ and Frank Reichenberger et al $1999(10 \%)$ given as additional diagnosis. ${ }^{[19,21]}$

EBB was performed in 15 cases in the present study and it was diagnostic in $60 \%$ cases. The similar results were obtained in various study i.e. Ashok Dasgupta et al 1999 (60\%), ${ }^{[19]}$ Thida Win et al $2003(61.4 \%)$ and David A. Schenk et al $1987(56 \%)$ and it was very high to the study 
Frank Reichenberger et al $1999(17 \%)$. $^{[20,21,23]}$

The low diagnostic yield of EBB in Frank Reichenberger et $\mathrm{al}^{[21]}$ study only $17 \%$ was because of more than 10 bronchoscopist had been introduced to bronchoscopy and the different diagnostic methods including handling, preparation was the fact and also stated that EBB was used very reluctantly in this study because many lesions were not accessible to the biopsy forceps. This discussion reveals that the training and expertise of bronchoscopist with preparation and handling of sample with or without ROSE significantly influenced the diagnostic yield of the procedure.

The EBB was solely diagnostic in $11 \%$ of cases in the present study which is very similar to the Thida Win et $\mathrm{al}^{\left[{ }^{[20]}\right.} 2003(12 \%)$ and it is higher to the Ashok Dasgupta et al $1999(3 \%) .{ }^{[19]}$ Moreover, the particular cell type of the tumor could influence yield from EBB. Crush artifacts produced during biopsy sampling of small cell cancer may result in a negative result. This situation was seen in two of the cases in which TBNA was diagnosed. Jones et al, ${ }^{[24]}$ have similarly reported on the critical diagnostic value of TBNA in five patients with small cell cancer who demonstrated crush artifacts on non-diagnostic EBB.

In the present study TBNA was performed in all 30 cases and found positive in 26(87\%) of cases. The results were consistent with study of Ashok Dasgupta et al, ${ }^{[19]} 1999$ $(85 \%)$ but higher to study i.e. Frank Reichenberger et al, ${ }^{[21]}$ (35\%), Thida Win et al 200320 (41.9\%), David A. Schenk et al $1987(45 \%) .{ }^{[23]}$ On comparison addition of TBNA for diagnostic procedure given the additional diagnostic yield comparably similar to Ashok Dasgupta et al, ${ }^{[19]}$ Frank Reichenberger et $a 1,{ }^{[21]}$ David A. Schenk et $a 1,{ }^{[23]}$ with present study. The higher results of TBNA in present study may be because of highly patients selection workup for malignancy, expertise of bronchoscopist, the choice of needle selection (19G), combination of TBNA technique and pathologist.

The TBNA was solely diagnostic in $31 \%(8 / 30)$ cases in the present study. Out of that 1 case has both EML \& SPD finding. In 5 cases had SPD, 2cases had only mediastinal lymphadenopathy and mass presentation without mucosal involvement.

The high results of TBNA in present study may be because of used 19G needle which gave good material for histopathological examination. These finding are consistent with the studies of Ashok Dasgupta et al $(20 \%),{ }^{[19]}$ Frank Reichenberger et al, ${ }^{[21]}(20 \%)$ and Benan Caglayan et al, ${ }^{[18]}$ $(34.3 \%)$. The overall diagnostic yield was in the present study 93\% with (CDP+TBNA) which is consistent with Ashok Dasgupta et al (96\%). ${ }^{[19]}$

Submucosal disease, as defined earlier, and peribronchial disease presenting as narrowing and extrinsic compression, have significantly lower yields with CDP. ${ }^{[25-27]}$ Shure and Fedullo25 showed an increased yield with TBNA (71\%) compared with EBB (55\%), similar to results obtained by Buirski et al, ${ }^{[26]}$ (EBB, 43\%; TBNA, 100\%). The individual yield from $\mathrm{EBB}$ and TBNA in our series $(\mathrm{EBB}=60 \%$; TBNA $=87 \%$ ) is similar to that reported in the above series.

The addition of TBNA to CDP increased the diagnostic yield in our study. In submucosal disease, involvement tends to occur in a submucosal plane along the lymphatics with minimal mucosal abnormality. Similarly, extrinsic compression from peribronchial disease tends to leave the mucosal surface predominantly intact. CDP using EBB or $\mathrm{BB}$ or $\mathrm{BW}$ tend to sample mainly the surface rather than deep within the lesion. In these situations, the ability of TBNA to provide adequate sampling by penetrating either the submucosa or directly through the bronchial wall into the tumor mass could enhance diagnostic yield. In our study the diagnostic yield of $67 \%$ with CDP, compared with the 93\% yield obtained by the addition of TBNA, is probably a reflection of this anatomic variation that occurs with SPD. Analysis of diagnostic yield from individual procedures and their combinations revealed several interesting facts. The best yield from any individual procedure was obtained with TBNA (87\%), followed by EBB (60\%), BB (47\%) and BW (27\%) In SPD, the yield from TBNA was far superior to the yield from any other individual procedure or their combination. Thus, use of TBNA alone or in combination with CDP would have diagnosed disease in all these patients. The best results being obtained by a combination of TBNA+EBB+ BB+BW (93\%). In the present study in the cases of SPD the diagnostic results are consistent with Ashok Dasgupta et al,,${ }^{[19]}$ and Benan Caglayan et al. ${ }^{[18]}$

\section{Conclusion}

We conclude that the overall diagnostic yield of flexible bronchoscopy procedure is increased in patients with EML or SPD by the addition of TBNA. The TBNA is a safe procedure that should be routinely used to increase diagnostic yield in patients with EML or SPD. In cases of SPD, TBNA should be considered the procedure of choice.

\section{References}

1. Crofton \& Douglas's: Lungcancer; Text book of Respiratory diseases 2010, 5;1077-79

2. Spiro SG, Porter JC. Lung cancer-where are we today? Current advances in staging and nonsurgical treatment. Am J Respir Crit Care Med 2002; 166: 1166-96.

3. Parkin DM, Pisani P, Ferlay J. Global cancer statistics. CA Cancer J Clin 1999; 49: 33-64.

4. Bhera D. Lung cancer in India; Indian Journal of Chest Diseases \& allied sciences 1992; 34:91-101.

5. Murrey JF and Nadal JA. Bronchogenic carcinoma; Text Book of Respiratory Medicine 1994; 2:1558-60.

6. Jindal SK, Behra D. Clinical spectrum of lung cancer: Review of Chandigarh experience of 10 years. Lung India 1990; 894-98.

7. Shure D, Fedullo PF. Transbronchial needle aspiration of peripheral masses. Am Rev Respir Dis 1983; 128:1090-1092.

8. Wang KP, Haponik EF, Britt EJ, Khouri N, Erozan YS. Transbronchial needle aspiration of peripheral pulmonary nodules. Chest 1984; 86: 819-23.

9. Schenk DA, Bryan CL, Bower JH, Myers DL. Transbronchial needle aspiration in the diagnosis of bronchogenic carcinoma. Chest 1987;92:83-5.

10. Wang KP, Marsh BR, Summer WR, Terry PB, Erosan YS, Baker RR. Transbronchial needle aspiration for diagnosis of lung cancer. Chest 1981; 80: 48-50.

11. Wang KP, Terry PB. Transbronchial needle aspiration in the diagnosis and staging of bronchogenic carcinoma. Am Rev Respir Dis 1983; 
127: $344-7$.

12. Horsley JR, Miller RE, Amy RWM, King EG. Bronchial submucosal needle aspiration performed through the fiberoptic bronchoscope. Acta Cytol 1984; 28: 211-7.

13. Wang KP, Terry PB, Marsh BR. Bronchoscopic needle aspiration biopsy of paratracheal tumors. Am Rev Respir Dis 1978; 118: 17-21.

14. Khoo K, Chua GSW, Mukhopadhyay A, et al. Transbronchial needle aspiration: initial experience in routine diagnostic bronchoscopy. Respir Med 2003; 97:1201-4.

15. Haponik EF, Capellari JO, Chin R, et al. Education and experience improve transbronchial needle aspiration performance. Am J Respir Crit Care Med 1995; 151:1998-2002.

16. Narang RK, Dubey AL, Gupta MC, Raju S. Primary bronchial carcinoma: A clinical study. Indian J Chest Dis Allied Sci 1977; 19:120-23.

17. Malhotra V, Malik R, Beohar PC, Gondal R, Khanna SK, Narayanan PS. Tumors of the lung: Histomorphological study. J Chest Dis Allied Sci 1986; 2:28-40.

18. Caglayan B, Akturk UA, Fidan A, Salepci B, Ozdogan S, Sarac G, et al. Transbronchial needle aspiration in the diagnosis of endobronchial malignant lesions: a 3-year experience. Chest 2005; 128: 704-8.

19. Dasgupta A, Jain P, Minai OA, et al. Utility of transbronchial needle aspiration in the diagnosis of endobronchial lesions. Chest 1999; 115:1237-41.
20. Thida Win MB BS, Susan Stewart MB B Chir, Ashley M Groves MB BS. Respir Care 2003; 48(6):602-5.

21. Reichenberger F, Weber J, Tamm M, Bolliger CT, Dalquen P, Perruchoud AP, Soler M. The value of transbronchial needle aspiration in the diagnosis of peripheral pulmonary lesions. Chest 1999; :116(3):704-8.

22. Kvale PA, Bode FR, Kini S. Diagnostic accuracy in lung cancer: comparison of techniques used in association with flexible fiberoptic bronchoscopy. Chest 1976; 69:752-7.

23. Schenk DA, Bryan CL, Bower JH, Myers DL. Transbronchial needle aspiration in the diagnosis of bronchogenic carcinoma. Chest 1987;92:83-5.

24. Jones DF, Chin R Jr, Cappellari JO, et al. Endobronchial needle aspiration in the diagnosis of small-cell carcinoma. Chest 1994; 105:1151-4.

25. Shure D, Fedullo PF. Transbronchial needle aspiration of peripheral masses. Am Rev Respir Dis 1983; 128:1090-2.

26. Buirski G, Calverley PMA, Douglas NJ, et al. Bronchial needle aspiration in the diagnosis of bronchial carcinoma. Thorax 1981; 36:508-11.

27. Lundgreen R, Bligman F, Angstrom T. Comparison of transbronchial fine needle aspiration biopsy, aspiration of bronchial secretion, bronchial washing, brush biopsy and forceps biopsy in the diagnosis of lung cancer. Eur J Respir Dis 1983; 64:378-85

Copyright: (C) the author(s), 2019. It is an open-access article distributed under the terms of the Creative Commons Attribution License (CC BY 4.0), which permits authors to retain ownership of the copyright for their content, and allow anyone to download, reuse, reprint, modify, distribute and/or copy the content as long as the original authors and source are cited.

How to cite this article: Mahich MK, Rathi G, Kumar M. The Utility of Transbronchial Needle Aspiration and Conventional Diagnostic Procedures in the Diagnosis of Bronchogenic Carcinoma. Asian J. Med. Res. 2019;8(3):TB01-TB05.

DOI: dx.doi.org/10.21276/ajmr.2019.8.3.TB1

Source of Support: Nil, Conflict of Interest: None declared.

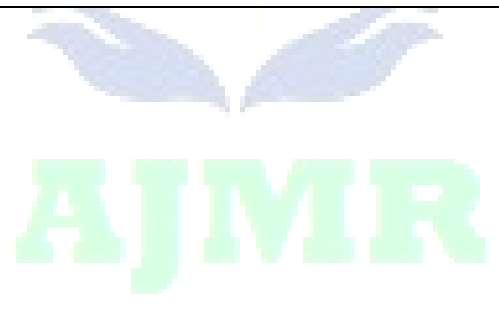

